\title{
Suggested investigations concerning unresolved experimental observations
}

\section{W. Westmeier ${ }^{1}$}

Institut für Kernchemie, Philipps-Universität Marburg

Hans-Meerwein-Straße, 35039 Marburg, Germany

E-mail: Westmeier@T-Online.de

\section{R. Brandt}

Institut für Kernchemie, Philipps-Universität Marburg

Hans-Meerwein-Straße, 35039 Marburg, Germany

E-mail: BrandtRestaff .uni-marburg.de

\section{S. Tyutyunnikov}

Joint Institute for Nuclear Research, VBLHEP

141980 Dubna near Moscow, Russian Federation

E-mail: tsi@sunse.jinr.ru

\begin{abstract}
A new concept is introduced for the classification of "unresolved problems" in the understanding of interactions in thick targets irradiated with relativistic ions: The centre-of-mass energy per nucleon of a hypothetical compound nucleus from a primary interaction, $\mathrm{E}_{\mathrm{CM}} / \mathrm{u}$, is calculated and correlated with several experimental observations in thick target irradiations. One observes in various reactions of relativistic primary ions with thick targets that there appears to be a threshold for reactions leading to "unresolved problems" which lies around $\mathbf{E}_{\mathbf{C M}} / \mathbf{u} \sim \mathbf{1 5 0} \mathrm{MeV}$ where $\mathrm{E}$ is the kinetic energy of the beam. A thick target is defined so that products from the first nuclear interaction will make secondary nuclear interactions. All "unresolved problems" are exclusively observed above this threshold, whereas below this threshold no "unresolved problems" are found.

Some considerations will be presented and further studies in this field are suggested.
\end{abstract}

XXI International Baldin Seminar on High Energy Physics Problems September 10-15, 2012

JINR, Dubna, Russia

1

Speaker 


\section{Introduction}

Spallation mass-yield curves in nuclear interactions with thin targets were systematically studied in many nuclear chemistry laboratories for decades around the world. These observed spallation mass-yield curves strictly obey well-known concepts of "limiting fragmentation" and "factorisation" and are well understood within current theoretical models. This applies for nuclear reaction studies induced by ions from $\mathrm{E}_{\text {total }}<1 \mathrm{GeV}$ and is extending up to $80 \mathrm{GeV}^{40} \mathrm{Ar}$ irradiations.

Articles have recently appeared describing "unresolved problems" in the study of nuclear interactions in thick targets induced by relativistic ions and their secondary reaction products ${ }^{[1,2]}$. Product yield distributions in thick copper targets from irradiations with $72 \mathrm{GeV}$ ${ }^{40} \mathrm{Ar}$ (at the LBNL, Berkeley), $44 \mathrm{GeV}{ }^{12} \mathrm{C}$ (at the JINR, Dubna), and $48 \mathrm{GeV}{ }^{4} \mathrm{He}$ (at CERN, Geneva) ${ }^{[3]}$ cannot be understood with well-established theoretical concepts, thus constituting "unresolved problems". Moreover, exceedingly large neutron emission during the irradiation of thick copper, lead and uranium targets with high energy heavy ion beams having $\mathrm{E}_{\text {total }}>30 \mathrm{GeV}$ have been observed in several laboratories; an exceedingly large neutron multiplicity is also considered to be an "unresolved problem".

All attempts to characterise unresolved problems in thick-target nuclear reactions since about $1954{ }^{[4]}$ have borne no fruit; the problem being that there are no defined ion energy, projectile mass, and target mass where these unresolved problems systematically occur.

We will introduce the following approach:

One calculates on a purely hypothetical basis the centre-of-mass energy $\mathrm{E}_{\mathrm{CM}}$ per nucleon in the entrance channel of the nuclear interaction. This entrance channel is defined by the kinetic energy $E_{P}$ of the primary ion (projectile) with mass $A_{P}$ and the target mass $A_{T}$. The value of $E_{C M}$ $/ \mathrm{u}$ in units of $\mathrm{MeV}$ is calculated as:

$$
\mathbf{E}_{\mathbf{C M}} / \mathbf{u}=\mathbf{E}_{\mathbf{P}} * \mathbf{A}_{\mathrm{T}} /\left(\mathbf{A}_{\mathbf{P}}+\mathbf{A}_{\mathrm{T}}\right) /\left(\mathbf{A}_{\mathbf{P}}+\mathbf{A}_{\mathrm{T}}\right)
$$

Experimental phenomena are produced in thick targets by primary ions (primaries) up to the end of their range and, in addition, by secondary fragments (secondaries) making nuclear interactions in the thick target. The relative importance of nuclear reactions in thick targets due to secondaries compared to primaries increases with the thickness of the target. One correlates the value $\mathrm{E}_{\mathrm{CM}} / \mathrm{u}$ - which might be taken as the hypothetical average excitation energy of each nucleon in the entrance channel of the reaction - with experimentally observed phenomena.

Some correlations are presented in Section 2 for increasing $\mathrm{E}_{\mathrm{CM}} / \mathrm{u}$. Obviously any observed correlation between $\mathrm{E}_{\mathrm{CM}} / \mathrm{u}$ of the entrance channel and interactions of secondary fragments in thick targets will not explain the reason for unresolved problems, but one does find a systematic dependence. In section 3 we will present some considerations which may be helpful as a start to understanding the observed order presented in Section 2. Section 4 contains our conclusions on the subject and new experiments are suggested which may help to shed light onto this rather old and complex set of unresolved problems. 


\section{Correlations between $E_{C M} / u$ and unresolved phenomena}

Unresolved problems as discussed in detail in Refs. [1,2] are observed only in high energy nuclear interactions with thick targets. Three types of experiments which reveal unresolved problems are described in more detail below:

\subsection{Production of ${ }^{24} \mathrm{Na}$ in two copper discs in contact}

The quantification of the isotope ${ }^{24} \mathrm{Na}\left(\mathrm{T}_{1 / 2}=15 \mathrm{~h}\right)$ produced in a thick copper target consisting of two $\mathrm{Cu}$-disks of $8 \mathrm{~cm}$ diameter and $1 \mathrm{~cm}$ thickness each in irradiations with relativistic ions requires just conventional gamma-ray spectrometry. Irradiations of two copper disks at various accelerators lasted only a few hours. After the irradiation, radioactive decay of

${ }^{24} \mathrm{Na}$ was measured in order to calculate with an accuracy of about $\pm 1 \%$ the activity ratio:

$$
\mathrm{R}_{0}\left({ }^{24} \mathrm{Na}\right)=\left({ }^{24} \mathrm{Na} \text { in downstream } \mathrm{Cu}\right) /\left({ }^{24} \mathrm{Na} \text { in upstream } \mathrm{Cu}\right)
$$

where "upstream $\mathrm{Cu}$ " denotes the $\mathrm{Cu}$-disk which is first hit by the beam and "downstream $\mathrm{Cu}^{\prime}$ ' is the following $\mathrm{Cu}$ disk. There may be several downstream disks in a very thick target stack.

Correlations of $\mathrm{E}_{\mathrm{CM}} / \mathrm{u}$ with experimental $\mathrm{R}_{0}\left({ }^{24} \mathrm{Na}\right)$-values are presented in Table 1 (column 3). In Reference [1] it was shown that $\mathrm{R}_{0}\left({ }^{24} \mathrm{Na}\right)>1.0$ constitutes an unresolved problem. This case of an unresolved problem is systematically observed for $\mathrm{E}_{\mathrm{CM}} / \mathrm{u}>192 \mathrm{MeV}$ as seen from the data presented in the third column of Table I. The third column is divided into two sub-columns in which consistent and inconsistent (=unresolved) data are listed separately. $\mathrm{R}_{0}\left({ }^{24} \mathrm{Na}\right)$ was not determined in reactions of $44 \mathrm{GeV}{ }^{12} \mathrm{C}$ on $\mathrm{Pb}$ and $\mathrm{U}$.

\subsection{Maximum of spallation product yields in two copper discs in contact}

Similarly to the activity ratio for the very distant spallation product ${ }^{24} \mathrm{Na}$, one can determine the yield ratio for any spallation product having nuclear charge $\mathrm{Z}$ and mass $\mathrm{A}$ as:

$$
\mathbf{R}_{\mathbf{0}}(\mathbf{A})=\left({ }^{\mathrm{A}} \mathbf{Z} \text { in downstream } \mathrm{Cu}\right) /\left({ }^{\mathrm{A}} \mathrm{Z} \text { in upstream } \mathrm{Cu}\right)
$$

Most product cross-sections measured some time after the end-of-bombardment are actually cumulative. One expects for standard-model nuclear reactions, based on the concept of "limiting fragmentation" and "factorisation", that $\mathrm{R}_{0}(\mathrm{~A})$ distributions have a maximum value close to the mass of the target nucleus, i.e. close to $A=63$ in a $\mathrm{Cu}$ target. The $\mathrm{R}_{0}(\mathrm{~A})$ distribution should then decrease continuously with decreasing product mass $\mathrm{A}$, i.e. with increasing mass difference $\Delta \mathrm{A}$ from the target mass. Detailed supporting arguments for the statement of continuous decrease of the mass distribution with rising mass difference $\Delta \mathrm{A}$ between target and product masses are given in Refs. [1, 2]. For thick targets two figures shall clarify the situation of resolved vs. unresolved results: In Figure 1 the $\mathrm{R}_{0}(\mathrm{~A})$ distribution is shown for the reaction of $7.3 \mathrm{GeV}^{2} \mathrm{H}$ on a thick $\mathrm{Cu}$ target [5]. The maximum value of spallation product ratios is found around mass $\mathrm{A}=57$ from where on the distribution goes slowly down with rising $\Delta \mathrm{A}$, which is perfectly consistent with standard theoretical model results. On the other hand, the $\mathrm{R}_{0}(\mathrm{~A})$ distribution 
measured from interactions of $72 \mathrm{GeV}^{40} \mathrm{Ar}$ on a thick $\mathrm{Cu}$ target [6] shown in Figure 2 has its maximum around mass $\mathrm{A}=51$ which is far below the target mass and which cannot be
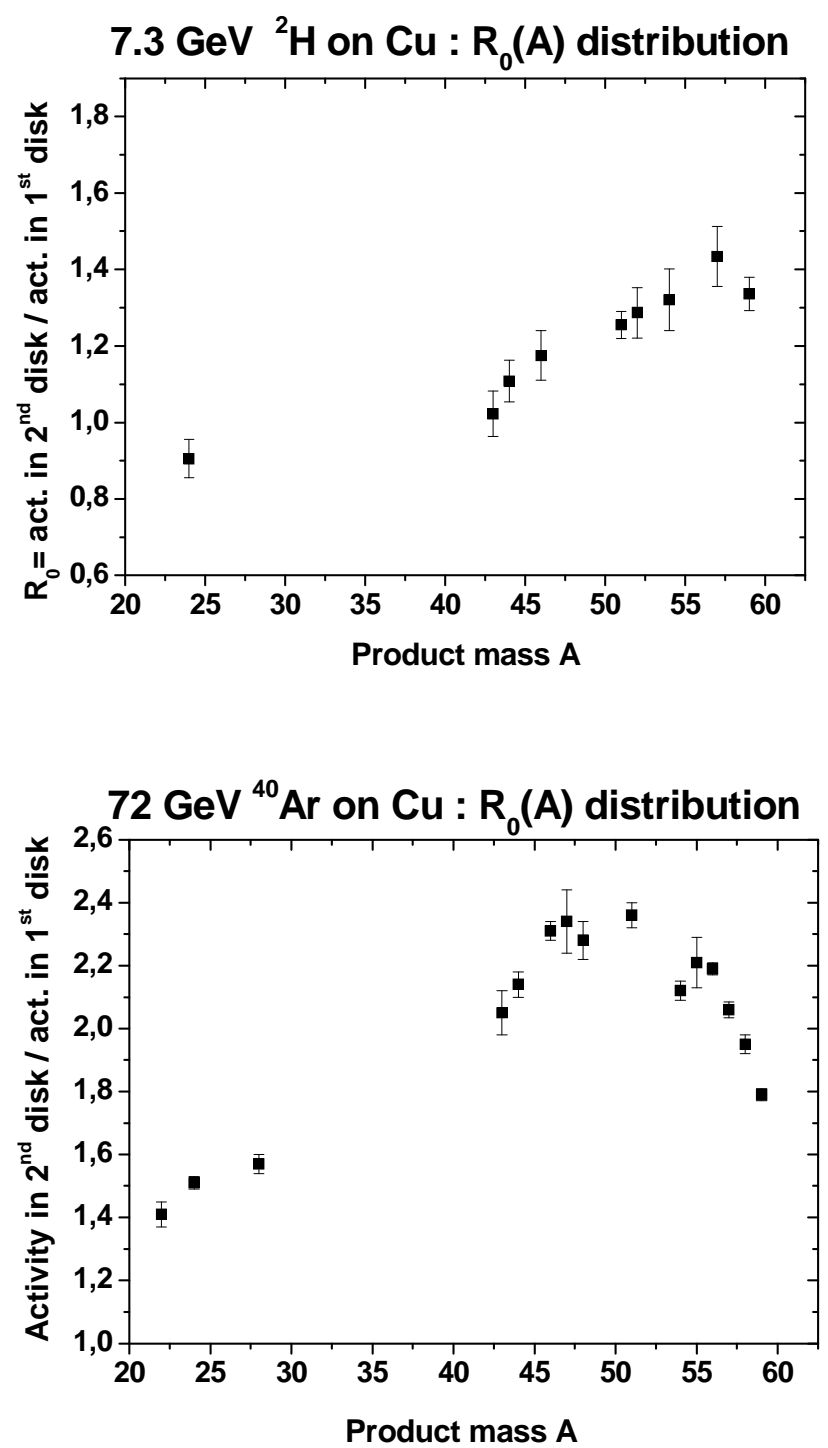
understood by current models.

\section{Figure 1:}

$\mathrm{R}_{0}(\mathrm{~A})$ distribution for the reaction of 7.3 $\mathrm{GeV}^{2} \mathrm{H}$ on a thick two-disks $\mathrm{Cu}$ target. The maximum is around mass 57 which is consistent with model calculations and it constitutes NO unresolved problem.

\section{Figure 2:}

$\mathrm{R}_{0}(\mathrm{~A})$ distribution for the reaction of $72 \mathrm{GeV}^{40} \mathrm{Ar}$ on two 1 -cm thick $\mathrm{Cu}$ target disks. The maximum is around mass 51 which is NOT consistent with model calculations and it is an unresolved problem.

In the former experiment (Figure 1) the cross-section ratio for the very distant spallation product ${ }^{24} \mathrm{Na}$ is below unity $(0.90 \pm 0.05)$, whereas it exceeds unity $(1.51 \pm 0.02)$ in the latter experiment (Figure 2). The system from Fig. 1 is well resolved and experimental results are in agreement with calculations, whereas the system from Fig. 2 is an unresolved problem. 


\subsection{Neutron emission from “GAMMA-2" target}

The GAMMA-2 target was described in several references [1,3]. It is a $20 \mathrm{~cm}$ long (thick) copper or lead spallation target, consisting of 20 metallic disks of $1 \mathrm{~cm}$ thickness and 8 $\mathrm{cm}$ diameter each. The metallic core is surrounded by a $6 \mathrm{~cm}$ thick paraffin moderator on all sides - with the exception of the front side, where the ion beam enters directly into the metallic target. The moderator surface contains small holes for plastic bottles containing low-energy neutron $(\mathrm{n}, \gamma)$ sensors, for example stable lanthanum salt. La-sensors measure directly the lowenergy neutron fluence via the reaction ${ }^{139} \mathrm{La}(\mathrm{n}, \gamma){ }^{140} \mathrm{La}$. The radioactive decay of ${ }^{140} \mathrm{La}$ is measured, thus allowing determination of the neutron production in the GAMMA-2 target during irradiation. All experimental results are compared with modern computer simulations, for example using the MCNPX2.7 code ${ }^{[2]}$.

Results of comparisons between experiments on the GAMMA-2 target and model calculations are listed in Table 1, last column. The agreement between experimental and calculated neutron yields is excellent for systems such as $\left(2 \mathrm{GeV}^{2} \mathrm{H}+\mathrm{Pb}\right)$ and $\left(1 \mathrm{GeV}{ }^{2} \mathrm{H}+\mathrm{Pb}\right)$. No unresolved problems are encountered. However, one observes about a factor of 3 times more neutrons experimentally than calculated in reactions of $44 \mathrm{GeV}{ }^{12} \mathrm{C}$ onto $\mathrm{Cu}, \mathrm{Pb}$, and U-targets ${ }^{[2]}$. This again constitutes another unresolved problem. Again, it seems to be the same threshold $\mathrm{E}_{\mathrm{CM}} / \mathrm{u}$ of primary interactions that separates resolved from unresolved thick target results.

Table 1: Correlations in nuclear interactions between $\mathbf{E}_{\mathrm{CM}}$ 峈 $\underline{\text { and several observables }}$

\begin{tabular}{|c|c|c|c|c|}
\hline Reaction & $\begin{array}{l}\mathrm{E}_{\mathrm{CM}} / \mathrm{u} \\
\mathrm{MeV}\end{array}$ & $\begin{array}{l}\mathrm{R}_{0}\left({ }^{24} \mathrm{Na}\right) \text { in } \mathrm{Cu}(*) \\
\leq 1.00>1.00\end{array}$ & $\mathrm{R}_{0}(\mathrm{~A})$ in $\mathrm{Cu}(* *)$ & $\begin{array}{c}\text { Neutron emission } \\
\text { in GAMMA-2 (***) }\end{array}$ \\
\hline $\begin{array}{c}48 \mathrm{GeV} \\
{ }^{4} \mathrm{He}+\mathrm{Cu}\end{array}$ & 664 & \begin{tabular}{c|c} 
& 1.21 \\
\pm 0.02
\end{tabular} & $\underline{\text { Problem }}$ & \\
\hline $\begin{array}{l}44 \mathrm{GeV} \\
{ }^{12} \mathrm{C}+\mathrm{Cu}\end{array}$ & 488 & $\begin{array}{r}1,24 \\
\pm \quad 0,02 \\
\end{array}$ & $\underline{\text { Problem }}$ & $\underline{\text { Problem }}$ \\
\hline $\begin{array}{l}72 \mathrm{GeV} \\
{ }^{40} \mathrm{Ar}+\mathrm{Cu}\end{array}$ & 426 & $\begin{array}{r}1.50 \\
\pm 0,02 \\
\end{array}$ & Problem & Problem \\
\hline $\begin{array}{l}24 \mathrm{GeV} \\
{ }^{1} \mathrm{H}+\mathrm{Cu} \\
\end{array}$ & 333 & $\begin{array}{r}1.10 \\
\pm 0.02 \\
\end{array}$ & $\underline{\text { Problem }}$ & \\
\hline $\begin{array}{l}25.2 \mathrm{GeV} \\
{ }^{12} \mathrm{C}+\mathrm{Cu}\end{array}$ & 279 & $\begin{array}{r}1.13 \\
\pm 0.03 \\
\end{array}$ & $\underline{\text { Problem }}$ & \\
\hline $\begin{array}{c}36 \mathrm{GeV} \\
{ }^{40} \mathrm{Ar}+\mathrm{Cu}\end{array}$ & 213 & $\begin{array}{r}1.17 \\
\pm \mathbf{0 . 0 2} \\
\end{array}$ & $\underline{\text { Problem }}$ & \\
\hline $\begin{array}{l}18 \mathrm{GeV} \\
{ }^{12} \mathrm{C}+\mathrm{Cu}\end{array}$ & 194 & $\begin{aligned} 1.08 \\
\pm 0.10\end{aligned}$ & $\underline{\text { Problem }}$ & \\
\hline $\begin{array}{l}22.4 \mathrm{GeV} \\
{ }^{22} \mathrm{Ne}+\mathrm{Cu}\end{array}$ & 192 & $\begin{aligned} & 1.08 \\
& \pm 0.02 \\
&\end{aligned}$ & & \\
\hline $\begin{array}{l}44 \mathrm{GeV} \\
{ }^{12} \mathrm{C}+\mathrm{Pb} \\
\end{array}$ & 189 & & & $\underline{\text { Problem }}$ \\
\hline $\begin{array}{l}44 \mathrm{GeV} \\
{ }^{12} \mathrm{C}+\mathrm{U}\end{array}$ & 168 & & & $\underline{\text { Problem }}$ \\
\hline
\end{tabular}




\begin{tabular}{|c|c|c|c|c|}
\hline $\begin{array}{l}7.3 \mathrm{GeV} \\
{ }^{2} \mathrm{H}+\mathrm{Cu}\end{array}$ & 107 & $\begin{array}{c}0.90 \\
\pm 0.05\end{array}$ & o.k. & o.k. \\
\hline $\begin{array}{l}4.5 \mathrm{GeV} \\
{ }^{1} \mathrm{H}+\mathrm{Cu} \\
\end{array}$ & 69 & $\begin{array}{r}0.98 \\
\pm \quad 0.05 \\
\end{array}$ & & \\
\hline $\begin{array}{l}14.7 \mathrm{GeV} \\
{ }^{4} \mathrm{He}+\mathrm{Pb} \\
\end{array}$ & 68 & & & o.k. \\
\hline $\begin{array}{c}4 \mathrm{GeV} \\
{ }^{4} \mathrm{He}+\mathrm{Cu} \\
\end{array}$ & 55 & $\begin{array}{c}0.92 \\
\pm 0,01 \\
\end{array}$ & & \\
\hline $\begin{array}{c}3 \mathrm{GeV} \\
{ }^{2} \mathrm{H}+\mathrm{Cu}\end{array}$ & 43 & $\begin{array}{c}0.90 \\
\pm 0,05\end{array}$ & o.k. & o.k. \\
\hline $\begin{array}{l}2.6 \mathrm{GeV} \\
{ }^{1} \mathrm{H}+\mathrm{Cu}\end{array}$ & 39 & $\begin{array}{c}0.96 \\
\pm 0.02\end{array}$ & & \\
\hline $\begin{array}{l}7.4 \mathrm{GeV} \\
{ }^{2} \mathrm{H}+\mathrm{Pb}\end{array}$ & 35 & & & o.k. \\
\hline $\begin{array}{c}6 \mathrm{GeV} \\
{ }^{4} \mathrm{He}+\mathrm{Pb} \\
\end{array}$ & 27 & & & o.k. \\
\hline $\begin{array}{l}1.3 \mathrm{GeV} \\
{ }^{1} \mathrm{H}+\mathrm{Cu} \\
\end{array}$ & 19 & $\begin{array}{r}0.99 \\
\pm 0.03 \\
\end{array}$ & & \\
\hline $\begin{array}{c}3 \mathrm{GeV} \\
{ }^{2} \mathrm{H}+\mathrm{Pb}\end{array}$ & 14 & & & o.k. \\
\hline $\begin{array}{l}2.0 \mathrm{GeV} \\
{ }^{1} \mathrm{H}+\mathrm{Pb}\end{array}$ & 10 & & & o.k. \\
\hline $\begin{array}{l}1.0 \mathrm{GeV} \\
{ }^{1} \mathrm{H}+\mathrm{Pb}\end{array}$ & 5 & & & o.k. \\
\hline
\end{tabular}

Notes for Table 1: Data in bold font stand for "unresolved problems"

(*) Only $\mathrm{R}_{0}\left({ }^{24} \mathrm{Na}\right) \leq 1.00$ is compatible with model calculations (see Ref. [1]).

The data are mostly taken from the $\mathrm{PhD}$ Thesis of Lerman,

the value for $22.4 \mathrm{GeV}^{22} \mathrm{Ne}$ on $\mathrm{Cu}$ is from the $\mathrm{PhD}$ Thesis of Haase as quoted in Ref. [1], the value for $18 \mathrm{GeV}^{12} \mathrm{C}$ on $\mathrm{Cu}$ is from the $\mathrm{PhD}$ Thesis of Ochs [5].

(**) $\quad \mathrm{R}_{0}(\mathrm{~A})$ in $\mathrm{Cu}$ is compatible with the experimental concept of "limiting fragmentation" and can be understood with model calculations, such as MCNPX2.7a when the maximum in $\mathrm{R}_{0}(\mathrm{~A})$ is close to $A_{\text {target }}=63$. When $A_{\max }$ is significantly below target mass the system exhibits an unresolved problem. For details see text and Figures 2\&3, and Ref. [2].

(***) The experimental neutron emission from $1 \mathrm{GeV}$ and $2 \mathrm{GeV}$ protons on lead is perfectly compatible with MCNPX2.7a calculations.

In summary one can see from Table 1:

All nuclear reactions - without any exception - having

\section{$\mathbf{E}_{\mathbf{C M}} / \mathbf{u}>150 \mathrm{MeV}$}

are associated with "unresolved problems", when investigated in thick targets.

All nuclear reactions - without any exception - having

\section{$\mathbf{E}_{\mathrm{CM}} / \mathbf{u}<110 \mathrm{MeV}$}

exhibit NO "unresolved problems", when their interactions are investigated in thick targets. So there is no worry about this latter class of nuclear interactions; theoretical model calculations agree with experimental findings. This is an important statement from a practical point-of-view. All low-energy nuclear interactions having practical relevance, such as in nuclear reactors or 
most accelerator applications are understood and modelled sufficiently well. They are not associated with any unresolved problem, especially with respect to excessive neutron production.

\section{Tentative interpretation of observed correlations}

The essential result presented so far is the clear separation of experimental phenomena associated with unresolved problems using the newly introduced parameter $\mathrm{E}_{\mathrm{CM}} / \mathrm{u}$. This parameter separates results into two classes as coming from reactions having average centre-ofmass energy per nucleon either smaller or larger than $150 \mathrm{MeV}$. At present we have no idea why this is so, but it is interesting to note agreement with statements from Hagedorn who also considered an energy (or temperature $\mathrm{T}_{0}$ ) of $158 \pm 3 \mathrm{MeV}$ ("Hagedorn limit") in a paper dating back to $1965^{[7]}$. He pointed out that above this limit one should expect to produce pions easily (their rest mass is just below $150 \mathrm{MeV}$ ). Therefore there should be some kind of upper limit in nuclear temperatures that are allowed to exist in nucleonic matter. We will not pursue this lineof-thinking any further at this point.

We continue our considerations with the empirical approach to separate the FIRST nuclear interaction induced by the primary ion from SECOND nuclear interactions induced by secondary fragments in a thick target. Furthermore, we focus on the interactions of primary ions in nuclear interactions in thick targets above the critical limit of $\mathbf{E}_{\mathbf{C M}} / \mathbf{u} \sim 150 \mathrm{MeV}$ which systematically show evidence of unresolved problems. Our interpretation of these phenomena suggests three hypothetical postulations:

\section{$\underline{1^{\text {st }} \text { postulation: }}$}

Small secondary fragments have properties that lead to reactions creating unresolved problems when they interact. In thin targets there is no possibility to interact, whereas further reactions of secondaries in thick targets expose the unresolved problems.

\section{$2^{\text {nd }}$ postulation:}

Secondary fragments created in a FIRST interaction with $\mathrm{E}_{\mathrm{CM}} / \mathrm{u}>150 \mathrm{MeV}$ have properties that change along their flight path.

How this change occurs is unclear at this stage, however, the fact that this change happens seems to be experimental fact, as will be shown below. We do not even know what the change is, but it could for example be a decay of the particle.

So far, there are few experiments known to the authors that show such a time-dependent change in nuclear properties without any external material interaction or particle emission within a time interval of $10^{-10}$ to $10^{-9}$ seconds. Evidence has been observed at the JINR in Dubna (Russia) in the irradiation of $20 \mathrm{Cu}$ disks of $1 \mathrm{~cm}$ thickness each with $44 \mathrm{GeV}{ }^{12} \mathrm{C}$ ions. The resulting $\mathrm{R}_{\mathrm{i}}\left({ }^{24} \mathrm{Na}\right)$ yield distribution ratio is shown in Figure 3, taken from Ref. [8]. One 
observes increasing $\mathrm{R}_{\mathrm{i}}\left({ }^{24} \mathrm{Na}\right)$ values up to about $10 \mathrm{~cm}$ target thickness. From there on the amount of product goes down as would be expected in a thick target where projectile density decreases through interactions. Even more interesting is the onset of enhanced ${ }^{24} \mathrm{Na}$-yield in a thick target which was measured with a stack of $20 \mathrm{Cu}$-foils of $1 \mathrm{~mm}$ thickness each ${ }^{[8]}$. In Figure 4 one can see that the yield ratio is just above unity over the first millimetres of target thickness (as expected) but then the ratio increases significantly thereafter. The activity ratio $\mathrm{R}_{\mathrm{i}}$ measured for the $2 \mathrm{~cm}$ target slab in Fig. 3 matches nicely the average of the $10 \mathrm{~mm}$ to $20 \mathrm{~mm}$ values from Fig. 4 as shown by the star sign in Fig. 3 .

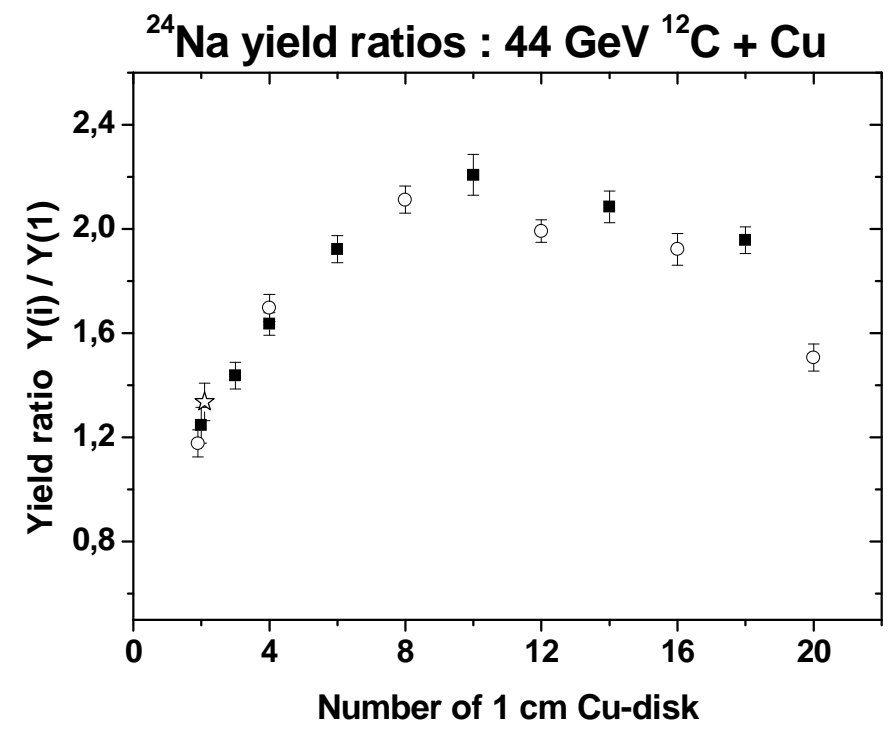

Figure 3:

Yield ratio of ${ }^{24} \mathrm{Na}$ in a stack of 20 disks (each $1 \mathrm{~cm}$ thick) of $\mathrm{Cu}$ irradiated with $44 \mathrm{GeV}^{12} \mathrm{C}$ at the Synchrophasotron in Dubna (Russia). The ${ }^{24} \mathrm{Na}$ contents in each foil is measured $\left(\mathrm{Y}_{\mathrm{i}}\right)$ and compared to the $1^{\text {st }} \mathrm{Cu}$ disk $\left(\mathrm{Y}_{1}\right)$. Different symbols denote different experiments. Data for the first point are displaced a little in X.
Figure 4:

Yield ratio of ${ }^{24} \mathrm{Na}$ in a stack of 20 foils (each $1 \mathrm{~mm}$ thick) of $\mathrm{Cu}$ irradiated with $44 \mathrm{GeV}^{12} \mathrm{C}$ at the Synchrophasotron in Dubna (Russia). The ${ }^{24} \mathrm{Na}$ contents in each foil is measured $\left(\mathrm{Y}_{\mathrm{i}}\right)$ and compared to the $1^{\text {st }} \mathrm{Cu}$ foil $\left(\mathrm{Y}_{1}\right)$. Some data points are averages of 2 foils.

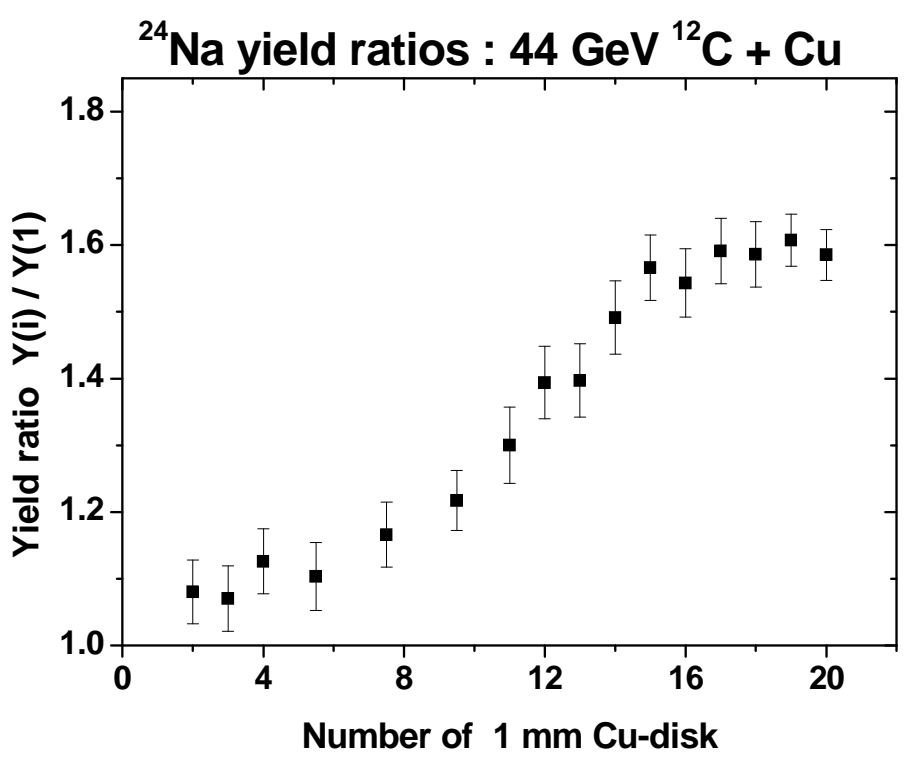


$3^{\text {rd }}$ postulation:

The last postulation is a very radical hypothesis:

When secondary fragments from an interaction having $E_{\mathrm{CM}} / \mathrm{u}>150 \mathrm{MeV}$ interact with another target nucleus, they transfer more energy than normally expected, i.e. they destroy this nucleus more radically than the primary ion would destroy the nucleus. This is the reason for the observation of enhanced neutron production mentioned earlier.

It may even be that secondary fragments remain together as a highly excited ensemble or convoy that disintegrates shortly afterwards.

Only future experiments will determine whether this third postulation proves to be an acceptable or fruitful suggestion. Further experiments and theoretical considerations are needed.

\section{Conclusions}

Various phenomena have been found in thick-target experiments induced by relativistic particles which are not in agreement with known reaction product systematics and crosssections. These phenomena are found when projectiles of very high energies interact with a thick target or a stack of thin targets. The experimental results are divided into two groups according to their agreement or not with theoretical model calculations as well as conformity with results from thin-target experiments.

Phenomena are denoted as "resolved" when:

- the mass distribution of spallation products follows the principles of limiting fragmentation and factorisation and the cross-section of very far spallation products, such as ${ }^{24} \mathrm{Na}$, is largest in the front of the target

- the measured neutron multiplicity is in agreement with model calculations

- the mean free path of secondary particles follows known systematics.

On the other hand, phenomena are "unresolved" when

- the mass distribution of spallation products in a second (or following) interaction is skewed towards large $\Delta \mathrm{A}$ and the cross-section of very far spallation products, such as ${ }^{24} \mathrm{Na}$, is significantly enhanced

- the neutron multiplicity exceeds expectation values from model calculations, which seems to indicate a very high energy transfer in the interaction of a secondary fragment

- the mean free path of secondary fragments is significantly shorter than expected from rangeenergy systematics.

These experimental phenomena are produced in thick targets by primary ions and, in addition, by secondary fragments making additional nuclear interactions in the thick target.

A hypothetical description of the average centre-of-mass excitation energy of each nucleon $\left(\mathrm{E}_{\mathrm{CM}} / \mathrm{u}\right)$ in the entrance channel of the reaction is correlated with experimentally observed phenomena. When one accepts this concept of $\mathrm{E}_{\mathrm{CM}} / \mathrm{u}$ of a hypothetical compound system, there seems to be a separating value of $\mathrm{E}_{\mathrm{CM}} / \mathrm{u}$ below which no unresolved phenomena at all are found and all reaction product cross-sections are in agreement with model calculations, 
whereas reactions with energies above the critical value of $\mathrm{E}_{\mathrm{CM}} / \mathrm{u}$, without any exception, lead to unresolved phenomena. However, due to scarcity of experimental results, the separating energy is not very well defined. Results from a reaction having $\mathrm{E}_{\mathrm{CM}} / \mathrm{u}=107 \mathrm{MeV}$ show no unexpected results whereas the outcome of a reaction having $\mathrm{E}_{\mathrm{CM}} / \mathrm{u}=168 \mathrm{MeV}$ is clearly "unresolved". We adopt a limiting value of $\mathrm{E}_{\mathrm{CM}} / \mathrm{u} \sim 150 \mathrm{MeV}$ as the critical energy separating resolved from unresolved reaction systems. This value is close to another limiting energy (or limiting temperature $\mathrm{T}_{0}$ ) of $158 \pm 3 \mathrm{MeV}$ which was introduced through considerations of statistical thermodynamics by Hagedorn long ago and which marks the transition energy from which on real hadrons are produced and "the number and longitudinal momentum of the secondaries produced would increase" ${ }^{[7]}$.

In order to define the transition energy more precisely, we wish to propose an experiment which scans over the limiting energy and will hopefully allow us to define it well. A simple and straightforward experiment is a thick-target experiment employing two or three copper disks of $1 \mathrm{~cm}$ thickness each in contact, which are irradiated with a beam of ${ }^{12} \mathrm{C}$. Beam energies of $0.6 \mathrm{GeV} / \mathrm{u}(7.2 \mathrm{GeV}$ kinetic energy), $0.9 \mathrm{GeV} / \mathrm{u}, 1.1 \mathrm{GeV} / \mathrm{u}, 1.2 \mathrm{GeV} / \mathrm{u}, 1.3 \mathrm{GeV} / \mathrm{u}$, $1.5 \mathrm{GeV} / \mathrm{u}$ and $1.8 \mathrm{GeV} / \mathrm{u}$ are recommended. The experiments scan the kinetic energy range around $1.2 \mathrm{GeV} / \mathrm{u}$ which corresponds to $\mathrm{E}_{\mathrm{CM}} / \mathrm{u}=158 \mathrm{MeV}$ for the ${ }^{12} \mathrm{C}+{ }^{65} \mathrm{Cu}$ reaction. If the hypothetical average excitation energy of $158 \mathrm{MeV}$ is actually a relevant limit, then $\mathrm{R}_{0}(\mathrm{~A})$ should indicate significant enhancement for masses A far away from the target mass. Moreover, the neutron dose-rate should rise over-proportional (it is 3 times more than expected for $44 \mathrm{GeV}$ ${ }^{12} \mathrm{C}$ induced reactions) when the limiting energy is exceeded. As interactions between nucleons inside a nucleus can be described by statistical thermodynamics, the limiting energy (or temperature) is not expected to be a sharp boundary but one rather expects to find a smooth onset of "unresolved" data around the limiting value.

\section{References}

[1] R. Brandt et al.,

"Interactions of relativistic heavy ions in thick heavy element targets - and some unresolved problems" (2008),

a. Physics of Elementary Particles and Nuclei 39(2), 507 - 526 (original), reprinted in

b. Physics of Particles and Nuclei $\underline{39(2)}, 259$ - 285

[2] S.R. Hashemi-Nezhad et al.

"Neutron production in thick targets irradiated with high energy ions" (2010), Physics Research International, Vol. 2011, Article IS128429, 12 pages,

doi: $10.1155 / 2011 / 128429$

[3] G. Dersch

„Kernchemische Studien zum Anomalonenphänomen bei Kernreaktionen mit relativistischen Schwerionen“"

PhD Dissertation, Philipps Universität Marburg (1986) 
[4] E. Rössle, E. Schopper, Absorptionsanalyse der sternauslösenden Komponenten der Ultrastrahlung, Zeitschrift für Naturforschung $\underline{9}$ (1954) 837 - 851

[5] M. Ochs, Experimente zur Neutronenfreisetzung durch Spallationsreaktionen in massiven Kupfer- und Bleitargets, PhD Dissertation, Philipps-Universität Marburg (1997), ISBN 3-89703-050-0

[6] K. Aleklett et al., Unusual behaviour of projectile fragments produced by the interactions of relativistic Ar ions with copper, Physical Review C38 (1988) 1658-1673 and Erratum: Physical Review C44 (1991) 566

[7] R. Hagedorn, Statistical Thermodynamics of Strong Interactions at High Energies, Supplemento Al Nuovo Cimento Vol. III (1965) 147-186

[8] R. Brandt et al., Untersuchung des anormalen Verhaltens relativistischer Fragmente aus Schwerionenreaktionen,

ISOTOPENPRAXIS 25 (1989) 433-438 